\title{
Fenofibrate increases the expression of high mobility group AT-hook 2 (HMGA2) gene and induces adipocyte differentiation of orbital fibroblasts from Graves' ophthalmopathy
}

\author{
Daniela Pasquali ${ }^{1}$, Giovanna Maria Pierantoni ${ }^{2}$, Alfredo Fusco ${ }^{2}$, Stefania \\ Staibano $^{3}$, Vittorio Colantuoni ${ }^{4,5}$, Annamaria De Bellis ${ }^{1}$ Antonio Bellastella ${ }^{1}$ and \\ Antonio Agostino Sinisi ${ }^{1}$
}

\footnotetext{
${ }^{1}$ Section of Endocrinology, Medico-Surgical Department of Clinical and Experimental Internal Medicine 'F. Magrassi e A. Lanzara', Research Center for Cardiovascular Disease, Second University of Naples, Departments of 'Cellular and Molecular Biology and Pathology 'L. Califano', ${ }^{3}$ Biomorphological and Functional Science and 'Biochemistry and Medical Biotechnologies, University of Naples 'Federico II', Naples, and ${ }^{5}$ Department of Biological and Environmental Sciences, University of Sannio, Benevento, Italy
}

(Requests for offprints should be addressed to A A Sinisi, Istituto di Endocrinologia, Seconda Università di Napoli, Building No. 16, Via Pansini 5, 80131 Napoli, Italy; Email: antonio.sinisi@unina2.it)

\begin{abstract}
Expansion of adipose tissue in the orbits is a key feature of Graves' ophthalmopathy. Recent evidence shows that orbital fibroblasts are committed to differentiate into adipocytes under appropriate stimuli. Rosiglitazone, an agonist of the nuclear hormone receptor, peroxisome proliferator-activated receptor $\gamma$ (PPAR $\gamma$ ) is able to induce both differentiation of orbital fibroblasts into mature adipocytes and expression of the TSH receptor (TSHr) gene. Several studies have suggested an important role of the high mobility group AT-hook 2 (HMGA2) gene in adipocytic cell growth and development. To investigate further the association between adipogenesis-related genes and orbital fibroblasts, we treated fibroblasts from Graves' ophthalmopathy (FGOs) and from normal orbital tissues with fenofibrate, a specific agonist for PPAR $\alpha$. We then evaluated the expression of the PPARa, PPAR 2, HMGA2, leptin and TSHr genes before and after $24 \mathrm{~h}$ of fenofibrate treatment, using semiquantitative and real-time PCR. For up to $96 \mathrm{~h}$ after exposure to fenofibrate, FGOs differentiated into adipocytes. PPAR $\alpha$ and PPAR $\gamma 2$ were expressed more in FGOs than in normal cultures, whereas TSHr mRNA was detected only in FGOs. Expression of HMGA2 mRNA and protein was significantly increased in FGOs from 6 to $24 \mathrm{~h}$ after fenofibrate, confirming its role in the early phase of adipocyte differentiation. Treatment with fenofibrate for $24 \mathrm{~h}$ significantly increased the expression of leptin and TSHr genes. Moreover, TSH treatment significantly increased the accumulation of CAMP, demonstrating that FGOs express functional TSHr. The high level of expression of PPAR other than PPAR $\gamma 2$ transcripts and the stimulating effect of fenofibrate on adipogenesis and on HMGA2, leptin and TSHr genes also indicate that the PPAR $\alpha$ pathway plays an important part in the adipocyte differentiation of FGOs. These findings suggest that novel drugs to antagonize PPAR $\alpha$, other than the PPAR $\gamma$ signalling system, may also need to be considered in the treatment or prevention of Graves' ophthalmopathy.
\end{abstract}

Journal of Molecular Endocrinology (2004) 33, 133-143

\section{Introduction}

In Graves' ophthalmopathy, mechanisms underlying orbital tissue proliferation remain unclear. On histology, the orbital tissue exhibits accumulation of glycosaminoglycan and overabundance of adipose tissue in the orbital muscles and connective tissues.
Fibroblasts derived from orbital connective tissue have an important role in Graves' ophthalmopathy and are composed of different subsets producing regulatory mediators that modulate regional inflammatory responses (Sorisky et al. 1996, Koumas et al. 2002, Smith 2002). They can differentiate into adipocytes that bear immunoreactive and 
functional thyroid-stimulating hormone receptor (TSHr) (Feliciello et al. 1993, Bahn et al. 1998). This observation has led several groups to search for the link between adipocyte differentiation, the appearance of adipogenic markers and expression of the TSHr gene.

The process of adipogenesis involves the interplay of several transcription factors. The discovery of the peroxisome proliferator-activated receptors (PPAR) $\alpha, \beta$ and $\gamma$, members of the nuclear receptor superfamily, and the identification of fatty acids and their derivatives as ligands of PPARs have revealed a new regulatory model of lipid action as a direct modulator of gene expression (Desvergne \& Wahli 1999). PPAR $\gamma$ is the major adipogenic transcription factor involved in terminal adipocyte differentiation (Tontonoz et al. 1994, Kubota et al. 1999, Rosen et al. 1999). PPARs act by binding to specific promoter response elements in association with the obligate heterodimerization partner, retinoid $\mathrm{X}$ receptor (RXR), which is activated selectively by 9-cis retinoic acid. Ligand-activated PPARs also regulate differentiation and clonal growth of several types of cancer cells (Kopelovich et al. 2002). Moreover, recent findings indicate a modulatory role for PPARs in controlling inflammation, which has potential therapeutic applications in chronic inflammatory diseases (Delerive et al. 2001).

Unsaturated fatty acids are specific natural ligands for PPARs. The thiazolidinedione hypoglycaemic agents such as rosiglitazone and pioglitazone are synthetic compounds that selectively bind $\operatorname{PPAR} \gamma$ and can induce adipocyte transformation of orbital fibroblasts from patients with Graves' ophthalmopathy and stimulate the expression of TSHr in vitro and in vivo (Valyasevi et al. 2002, Starkey et al. 2003). The possible role of PPAR $\alpha$ agonists, such as the fibrates, in adipocyte differentiation of fibroblasts from Graves' ophthalmopathy (FGOs) remains unexplored, but it has been shown that fibrates are able to induce adipogenesis in other fibroblast lines (Brandes et al. 1986). In addition, the pathways involved in adipocytic differentiation of orbital fibroblasts are putative.

Several studies have suggested an important role of the high mobility group AT-hook 2 (HMGA2) gene in adipocyte growth and development (Zhou et al. 1995, Battista et al. 1999, Anand \& Chada 2000, Arlotta et al. 2000). The HMGA family is comprised of four proteins (HMGAla, HMGAlb, HMGAlc, HMGA2) which are involved in the regulation of chromatin structure and function (Johnson et al. 1989, Manfioletti et al. 1991, Falvo et al. 1995). Overexpression of HMGA proteins is a necessary event in in vivo cell transformation (Chiappetta et al. 1995, Fedele et al. 1996, Bandiera et al. 1998). Moreover, HMGA2 ${ }^{-/-}$mice express a pygmy phenotype, together with a drastic reduction $(87 \%)$ in adipose tissue. Conversely, mice carrying a truncated HMGA2 gene showed an obese phenotype. Moreover, it has been found that HMGA2 gene was not expressed in wild-type adipose tissue, whereas it was expressed in fat deposits of both wild-type and genetically obese mice (Lep ob/Lep ob and Leprdb/Leprdb) after 1 week of a high fat diet, and that disruption of the HMGA2 gene prevents both diet- and gene-induced obesity (Zhou et al. 1995, Battista et al. 1999, Anand \& Chada 2000, Arlotta et al. 2000).

In order to clarify the interplay between adipocyte differentiation of orbital fibroblasts and genes related to adipogenesis, we studied the expression of PPARa, PPAR 2, HMGA2, leptin and TSHr before and after exposure to fenofibrate, an agonist of PPARa, using fibroblasts derived from orbital tissues from patients with Graves' ophthalmopathy and from individuals without thyroid-associated ophthalmopathy.

\section{Material and methods}

\section{Origin of tissues and cell cultures}

Orbital connective tissues were obtained from 12 patients with Graves' ophthalmopathy during orbital decompression surgery. The diagnosis was based on endocrine and ophthalmological criteria, including laboratory determination of hormones and antibodies and imaging studies (ultrasonography, computed tomography or magnetic resonance scan) of orbits. The patients (nine women, three men; aged 31-68 years), currently euthyroid, had never been treated with steroids or had been off treatment for more than 6 months. Orbital tissue controls were obtained from seven individuals (five women, two men; aged 33-67 years) undergoing eye surgery for trauma, osteoma or strabismus. None of the control individuals had a history of autoimmune or thyroid diseases or was affected by orbital inflammatory disorders. 
Table 1 Oligonucleotide sequences used for RT-PCR

\begin{tabular}{|c|c|c|}
\hline & Sequence $\left(5^{\prime}-3^{\prime}\right)$ & Size of PCR product (bp) \\
\hline \multicolumn{3}{|l|}{ Gene } \\
\hline & 5'-CCAGTATTTAGGAAGCTGTCC-3' & \\
\hline PPARa & $\begin{array}{l}\text { 5'-AAGTTCTTCAAGTAGGCCTCG-3' } \\
\text { 5'-GCGATTCCTTCACTGATAC-3' }\end{array}$ & 492 \\
\hline$P P A R \gamma 2$ & 5'-GCATTATGAGACATCCCCAC-3' & 580 \\
\hline $\operatorname{TSHr}(e d)$ & $\begin{array}{l}\text { 5'-GGGCGGAATGGGGTGTTCGT-3' } \\
\text { 5'-TTGGTCAGGTCAGGGAACAT-3' }\end{array}$ & 380 \\
\hline 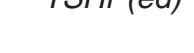 & 5'-ATCATGGTTGGGGGCTGGGT-3' & 300 \\
\hline $\operatorname{TSHr}(\mathrm{tm})$ & $\begin{array}{l}\text { 5'-TAGTCATCCTTCCATGTTGTG-3' } \\
\text { 5'-CACCAAAACCCTCATCAAGA-3' }\end{array}$ & 586 \\
\hline Leptin & $\begin{array}{l}\text { 5'-TGCTCAGAGCCACCACCTTC-3' } \\
\text { 5'-CGAAAGGTGCTGGGCAGCTCCGG-3' }\end{array}$ & 350 \\
\hline HMGA2 & $\begin{array}{l}\text { 5'-CCATTTCCTAGGTCTGCCTCTTG-3' } \\
\text { 5'-GACCCCTTCATTGACCTCAACTATG-3' }\end{array}$ & 350 \\
\hline GAPDH & 5'-GTCCACCACCCTGTTGCTGTAGCC-3' & 876 \\
\hline
\end{tabular}

Tissue explants were minced and immediately placed on plastic culture dishes for incubation with the appropriate medium in a humidified incubator $\left(37^{\circ} \mathrm{C}, 5 \% \mathrm{CO}_{2}\right)$. Fibroblasts were allowed to proliferate in Dulbecco's Modified Eagle medium (DMEM) supplemented with L-glutamine, 10\% (vol/vol) fetal bovine serum (FBS) and antibiotics (Gibco Brl, LifeTechnologies), as described previously (Pasquali et al. 2000).

\section{Isolation of mRNA and semiquantitative RT-PCR}

Total RNA was isolated from the cell cultures at the first passage. Total RNA was recovered with TRIzol (Invitrogen). Residual DNA was removed by treatment with Rnase-free DNase I (Promega). RNAs were reversely transcribed using $5 \mu \mathrm{g}$ total RNA after annealing with $0 \cdot 2 \mathrm{nM}$ oligo(deoxythymidine) for priming of cDNA in the presence of reverse transcriptase (Superscript, $200 \mathrm{U}$; Invitrogen) at $37^{\circ} \mathrm{C}$ for $1.5 \mathrm{~h}$. The reaction was stopped by incubation at $95^{\circ} \mathrm{C}$ for $5 \mathrm{~min}$. To obtain a negative control for the amplification reactions, we carried out an RNA transcription without adding reverse transcriptase enzyme. Complementary DNA (400 ng cDNA) obtained by reverse transcription of RNAs was amplified in a total volume of $50 \mu \mathrm{l}$ Tris $\mathrm{HCl} 10 \mathrm{mmol}, 1.5 \mathrm{mmol}$ $\mathrm{MgCl}_{2}$ and $50 \mathrm{mmol} \mathrm{KCl} \mathrm{pH} \mathrm{8 \cdot 3,} 100 \mathrm{ng}$ of 5'-3' end primers as described previously (Pasquali et al. 1999, 2000, 2002).

To evaluate variability in the expression of PPARa, PPARy2, HMGA2, leptin and TSHr, a semiquantitative RT-PGR was performed in which these genes were amplified with glyceraldehyde 3-phosphate dehydrogenase (GAPDH) as described previously (Pasquali et al. 1999, 2002). Briefly, before semiquantitative PCR, the number of cycles was chosen from the middle of the exponential phase of the reaction, separately for each gene type. To establish the number of cycles, GAPDH was amplified at 15, 22, 32 and 40 PCR cycles; PPARa, PPAR 2, TSHr and leptin were subjected to 25, 35 and 40 amplification cycles in separate experiments (data not shown). The following PCR conditions were used: 35 cycles of amplification at $94{ }^{\circ} \mathrm{C}$ for $1 \mathrm{~min}, 60^{\circ} \mathrm{C}$ for $1 \mathrm{~min}, 72^{\circ} \mathrm{C}$ for $1 \mathrm{~min}$ for $P P A R a$, PPAR 2, leptin and TSHr; 35 cycles at $94^{\circ} \mathrm{C}$ for $1 \mathrm{~min}, 65^{\circ}$ for $30 \mathrm{~s}, 72^{\circ} \mathrm{C}$ for $30 \mathrm{~s}$ for HMGA2; 25 cycles for GAPDH. For the semiquantitative RT-PCR, 100 ng GAPDH primers were added to each PGR reaction after the first 10 cycles as internal control, and the 876 bp product of $G A P D H$ was detected in each PCR reaction.

The levels of mRNAs, quantified by densitometry scanning of the amplification products electrophoresed on agarose gels, are expressed as the ratio between the density of each gene product and coamplified GAPDH as reported previously (Pasquali et al. 1999, 2002). The oligonucleotide sequences for PPARa, PPAR 2, HMGA2, leptin, $T S H r$ and GAPDH are shown in Table 1. Using specific primers with $\mathrm{PCR}$, we amplified the $\mathrm{B}-\mathrm{C}$ region of the extracellular domain and the $\mathrm{D}-\mathrm{F}$ region of the transmembrane domain of the $\mathrm{TSH} r$ gene, corresponding to nucleotides 158-537 and 


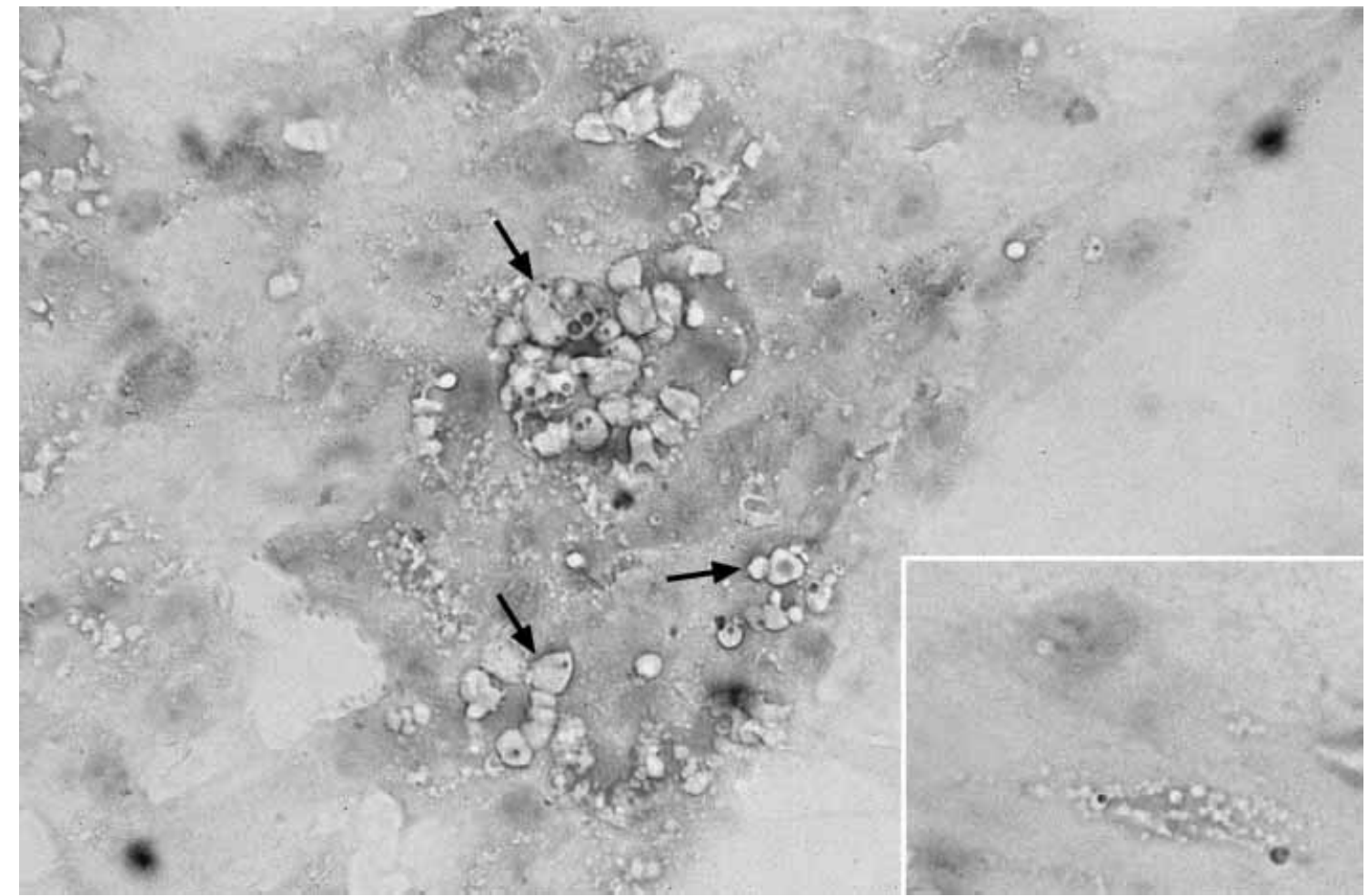

Figure 1 Photomicrograph showing Oil Red $\mathrm{O}$ staining of human cultured orbital fibroblasts from a patient with Graves' ophthalmopathy and (inset) from a control patient treated for $96 \mathrm{~h}$ with $500 \mu \mathrm{M}$ fenofibrate (original magnification $\times 100$ ). The arrows indicate the presence of triacylglycerol inclusions in these cells.

1720-2306 respectively (Table 1 ). PCR products were then separated on a $1 \cdot 2 \%$ agarose gel containing ethidium bromide using a 100 bp DNA ladder (Gibco Brl, Life Technologies) as size marker.

\section{Quantitative RT-PCR}

Real-time quantitative PCR was used to determine the amounts of PPAR $\alpha$, PPAR $\gamma 2$, HMGA2, leptin and TSHr mRNA. This PGR method monitors the progress of the PCR via detection of fluorescent signals released by $T a q$ polymerase from a specific probe that contains both fluorescent dye and quencher. In these experiments, the amount of specific amplicon present was related to $\beta_{2}$ microglobulin and subsequently to an internal control. RNA was extracted from primary cultures of orbital F from patients with Graves' ophthalmopathy as described above. RNA was reverse transcribed to first cDNA as described previously.

Real-time PCR was repeated three times for each sample using the following primers: PPARa, 5'-ATGGCATCGAGAACAAGGAG-3' (sense) and 5'-GGGGAATATGGGGTCATAAA-3' (antisense); PPAR 2, 5'-TGAATGTGAAGCGCATTGAA-3' (sense) and 5'-CTGCAGTAGCTGGACGTG TT-3' (antisense); HMGA2, 5'-GGCGAGCTCAT AAAATGGAA-3' (sense) and 5'-TACTGTTCGA TTGGCGACAA-3' (antisense); leptin, 5'-GGCTT TGGCCGTATCTTTTC-3' (sense) and 5'-CCAA ACGGGTGACTTTCTGT-3' (antisense); TSHr, 5'-ACGCAGGGGACAAAGATACG-3' (sense) and 5'-GAATGGATTGGCACAGGAGT-3' (antisense). Real-time PCR was also repeated three times for a housekeeping gene, $\beta_{2}$-microglobulin. The following primers were used: sense, 5'-CGAGCAG AGAATGGAAAGTC-3'; antisense, 5'-GATGGT GCTTACATGTCTCG-3'. The iQ SYBR Green Supermix kit (Bio-Rad Laboratories) was used in an iCycler iQ Real-Time PGR Detection System (Bio-Rad Laboratories). Data are expressed as the amount of specific PGR product of each gene in cells treated with fibrate $(500 \mu \mathrm{M})$ divided by that in 


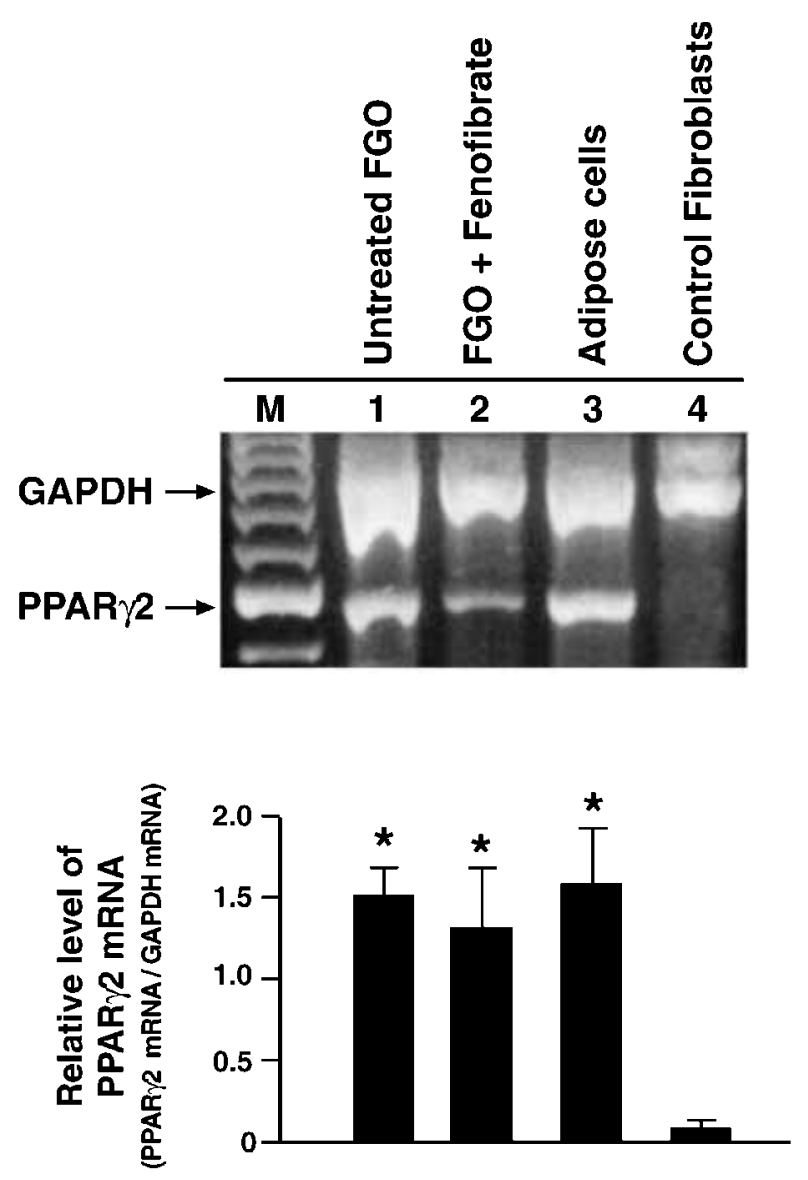

Figure 2 PPAR $\gamma 2$ mRNA levels in orbital FGOs with or without fenofibrate and in control cells. M, 100 bp DNA ladder; Lane 1, untreated FGOs; Lane 2, FGOs treated with fenofibrate $500 \mu \mathrm{M}$; Lane 3, adipocytes from breast tissues; Lane 4, orbital fibroblasts obtained from control patients. Values for PPAR $\gamma 2$ mRNA are expressed as arbitrary densitometric units. Data are means \pm S.D. $(n=3) ;{ }^{\star} P<0.05$ compared with untreated Control.

untreated cells after normalization based on the housekeeping gene product, $\beta_{2}$-microglobulin (which showed no significant difference in any treatment).

\section{Protein extraction, western blotting and antibodies}

Protein samples from orbital FGOs were extracted with Nonidet-P40 (NP-40) lysis buffer supplemented with $50 \mathrm{mM}$ sodium fluoride, $0.5 \mathrm{mM}$ sodium vanadate, $0.5 \mathrm{mM}$ phenyl methylsulphonyl fluoride, $5 \mathrm{mg} / \mathrm{ml}$ aprotinin and $5 \mathrm{mg} / \mathrm{ml}$ leupeptin. Protein concentration was estimated by a
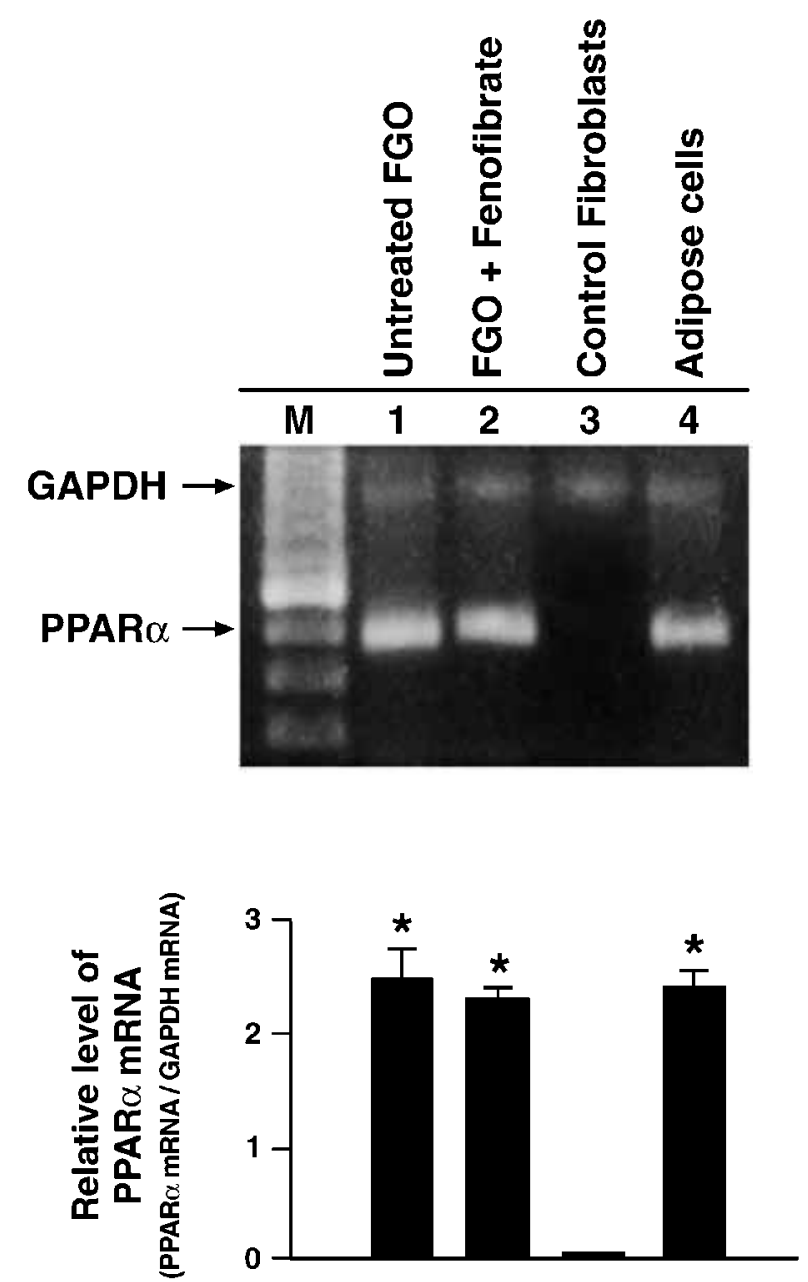

Figure 3 PPAR $\alpha$ mRNA levels in orbital FGOs in primary culture with or without fenofibrate and in control cells. M, 100 bp DNA ladder; Lane 1, untreated FGOs; Lane 2, FGOs treated with fenofibrate $500 \mu \mathrm{M}$; Lane 3, orbital fibroblasts obtained from control patients; Lane 4, adipocytes from breast tissues. PPAR $\alpha$ mRNA are expressed as arbitrary densitometric units. Data are means \pm S.D. $(n=3) ;{ }^{*} P<0.05$ compared with untreated Control.

modified Bradford assay (Bio-Rad Laboratories). The protein extracts were boiled in Laemmli sample buffer, separated by sodium dodecyl sulphate-polyacrylamide gel electrophoresis (SDSPAGE) and transferred to nitrocellulose membranes (Hybond C, Amersham Inc.). Membranes were blocked with $5 \%$ non-fat milk proteins and incubated with the antibody at the appropriate dilution. The antibodies directed against the HMGA2 protein are described elsewhere (Santulli et al. 2000). Bound antibodies were detected by 


\section{Real-time PCR}

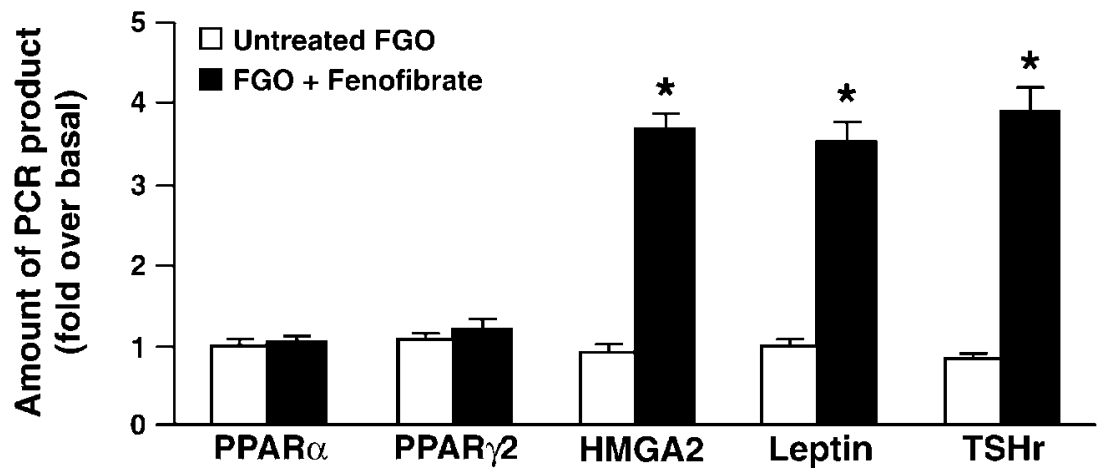

Figure 4 Modulation of PPAR $\alpha$, PPAR $\gamma 2$, HMGA2, leptin and TSHr mRNA levels by fenofibrate treatment in FGOs. Cells were cultured with or without fenofibrate $(500 \mu \mathrm{M})$ for $24 \mathrm{~h}$. Real-time PCR products of PPAR $\alpha$, PPAR $\gamma 2$, HMGA2, leptin and TSHr were standardized against a housekeeping gene product $\left(\beta_{2}\right.$-microglobulin) in each experiment. Data are means \pm S.D. $(n=3)$; ${ }^{\star} P<0.05$ compared with untreated FGO.

horseradish peroxidase-conjugated secondary antibodies followed by enhanced chemiluminescence (Amersham Inc). As a control for equal loading of protein lysates, the blotted proteins were probed with antibodies against $\gamma$-tubulin.

\section{Oil Red O staining}

Orbital fibroblast cultures were plated in one-well culture chamber slides (Nunc plasticware, Life Technologies) in DMEM supplemented with $10 \%$ FBS, grown to confluence and, after $24 \mathrm{~h}$ of serum starvation, treated with or without $500 \mu \mathrm{M}$ fenofibrate (Sigma) in DMEM supplemented with 1\% FBS up to $96 \mathrm{~h}$. Cells were washed with $1 \times$ PBS, fixed in $10 \%$ formalin overnight at room temperature, and rinsed in 60\% isopropanol before staining with filtered $0.21 \%$ Oil Red O in isopropanol for $1 \mathrm{~h}$. Washed cells were exposed to haematoxylin solution for $5 \mathrm{~min}$, rinsed with tap water and visualized using a microscope (Leitz Laborlux, Leica Imaging System, Inc., Cambridge, England).

\section{Accumulation of cyclic adenosine monophosphate}

Confluent orbital FGOs and fibroblasts from control monolayers in six-well plates (Costar, Milan, Italy) were starved for $24 \mathrm{~h}$ in medium without FBS, then shifted to medium supplemented with $1 \%$ FBS and phosphodiesterase inhibitor. The cells were treated with forskolin $10 \mathrm{mM}$ or bovine TSH $10 \mathrm{mU} / \mathrm{ml}$ and 3-methyl-1-isobutylxanthine $(0.5 \mathrm{mM})$. After $30 \mathrm{~min}$, cultures were interrupted by adding cold $70 \%$ ethanol. After overnight incubation in ethanol, the supernatant was collected, centrifuged and dried. The extracts were reconstituted with the appropriate buffer and processed for the cAMP assay using an RIA kit (Amersham Inc).

\section{Statistical analysis}

The data are expressed as the mean \pm s.D. $(n=3)$ from at least three separate experiments performed in triplicate. Data were subjected to analysis of variance, followed by Fisher's LSD multiple comparison test using NCSS software (J. Hintze, Kaysville, UT, USA). Values of $P<0.05$ were considered statistically significant.

\section{Results}

\section{Fenofibrate treatment induces adipocyte differentiation in FGOs}

To test the hypothesis that fenofibrate could induce adipocyte differentiation in FGOs, we treated FGOs and control fibroblasts with or without $500 \mu \mathrm{M}$ fenofibrate for up to $96 \mathrm{~h}$. Few subpopulations $(1-2 \%)$ of FGOs exposed to fenofibrate changed their typical fibroblastic appearance after $24 \mathrm{~h}$ of exposure to fenofibrate (data not shown). 
Treatment with fenofibrate for up to $96 \mathrm{~h}$ resulted in strong adipocyte differentiation in $35 \%$ of FGOs, compared with $1-2 \%$ of control cell culture by Oil Red O staining (Fig. 1). Oil Red O staining was negative in untreated cells (data not shown). After 3-4 days of treatment, FGOs assumed a spherical shape with some intracytoplasmic vacuoles visible under phase-contrast microscope, indicating accumulation of triglycerides (Fig. 1).

\section{PPAR $\alpha$, PPAR $\gamma 2$, leptin and TSHr mRNA are expressed in FGOs, and fenofibrate significantly increases leptin and TSHr mRNA levels}

PPAR $\alpha$ and PPAR $\gamma 2$ mRNA were expressed at high level in FGOs, and were almost undetectable in control fibroblasts (Figs 2 and 3 respectively). Adipose cells from breast tissues obtained from patients undergoing mastectomy for gynaecomastia served as the positive controls (Figs 2 and 3). Fenofibrate treatment did not significantly modify the level of PPAR $\alpha$ and PPAR $\gamma 2$ transcripts (Figs 2, 3 and 4). Leptin (Fig. 5) transcript was detected in FGOs, and increased significantly after $24 \mathrm{~h}$ of fenofibrate treatment, while the level of expression in control fibroblasts was barely detectable (data not shown). The $\mathrm{B}-\mathrm{C}$ region of the extracellular domain and the $\mathrm{D}-\mathrm{F}$ region of the transmembrane domain of the TSHr gene were absent in control fibroblasts (Fig. 6). Both extracellular domain and transmembrane portions of TSHr were detected in untreated FGOs and were increased after $24 \mathrm{~h}$ of fenofibrate treatment (Fig. 6). The real-time PCR results were similar to those of semiquantitative analysis, confirming the above results. In particular, the levels of PPAR $\alpha$ and PPAR $\gamma 2$ transcripts were increased only slightly, and not significantly, by fenofibrate, whereas leptin and TSHr transcripts were increased significantly after $24 \mathrm{~h}$ of fenofibrate treatment $(P<0 \cdot 05)$ (Fig. 4).

\section{HMGA2 mRNA and protein are expressed in FGOs and are modulated by fenofibrate}

To investigate whether the expression of HMGA2 was related to adipocyte differentiation of FGOs, we treated FGOs with fenofibrate for different periods of time, to induce adipocytic differentiation. As shown in Fig. 7A, the early adipocyte differentiation of FGOs induced by fenofibrate was accompanied by a remarkable increase in HMGA2
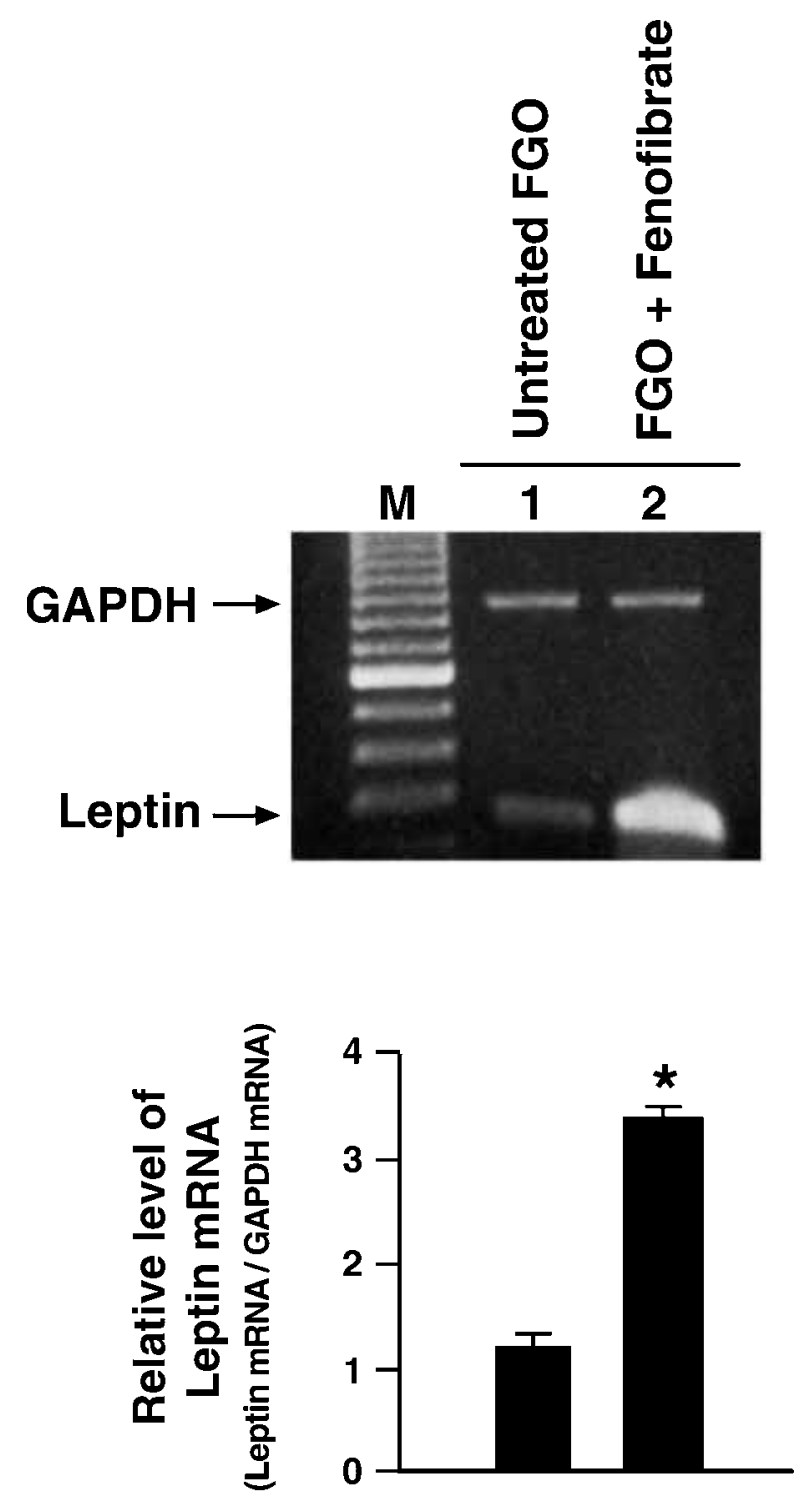

Figure 5 Analysis of leptin expression in orbital FGOs in primary culture undergoing adipocyte differentiation. M, 100 bp DNA ladder; Lane 1, untreated FGOs; Lane 2, FGOs treated with fenofibrate $500 \mu \mathrm{M}$. Leptin mRNA levels are expressed as arbitrary densitometric units. Data are means \pm S.D. $(n=3) ;{ }^{\star} P<0.05$ compared with untreated FGO.

mRNA levels. This increase was already detectable $6 \mathrm{~h}$ after the stimulation with fenofibrate; it persisted at 12 and $24 \mathrm{~h}$, and was confirmed by real-time-PCR analysis (Fig. 4), which showed a significant increase in HMGA2 mRNA after $24 \mathrm{~h}$ of exposure to fenofibrate. This corresponded to the time at which adipocyte differentiation was first detected by Oil Red $\mathrm{O}$ staining. Findings from 


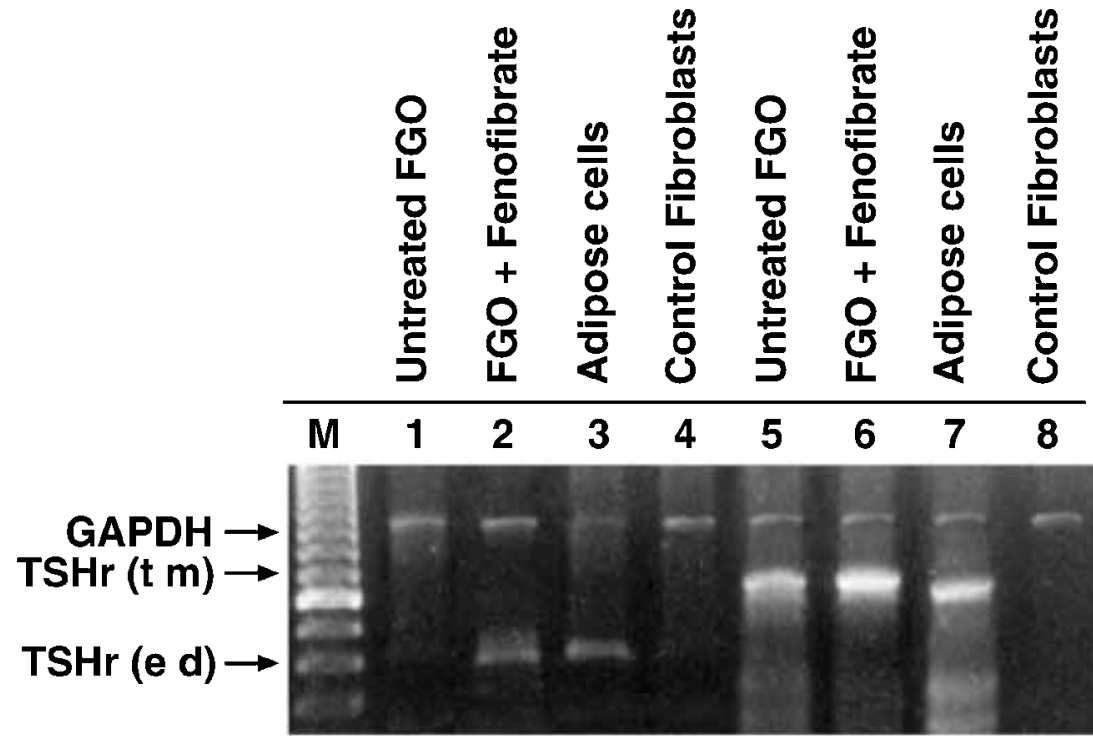

Figure 6 Analysis of TSHr expression in FGO adipocyte differentiation, in the transmembrane (t $\mathrm{m}$ ) and extracellular (e d) domains. M, 100 bp DNA ladder; Lane 1, TSH receptor (TSHr) extracellular domain mRNA in untreated FGOs; Lane 2, TSHr extracellular domain mRNA in fenofibrate treated FGOs; Lane 3, TSHr extracellular domain mRNA in adipose cells from breast tissues; Lane 4, TSHr extracellular domain mRNA in primary culture of orbital fibroblasts from control individuals; Lane 5, TSHr transmembrane domain mRNA in untreated FGOs; Lane 6, TSHr transmembrane domain mRNA in fenofibrate FGOs; Lane 7, TSHr transmembrane domain mRNA in adipose cells from breast tissues; Lane 8, TSHr transmembrane domain mRNA in orbital fibroblasts from control individuals.

western blot analysis of untreated and fenofibratetreated FGOs paralleled those obtained with RT-PGR (Fig. 7B). We used a thyroid carcinoma cell line, FB-2, as positive control (Fig. 7) (Basolo et al. 2002). HMGA2 mRNA was undetectable in control fibroblasts (data not shown).

\section{FGOs expresses functional TSHr}

To demonstrate that the TSHr found by RT-PCR in FGOs was functional, we assayed the accumulation of cAMP under basal conditions and after 30 min of treatment with forskolin or bovine TSH. In FGOs, exposure to TSH or forskolin stimulated the accumulation of cAMP significantly $(P<0.05)$ (Fig. 8).

\section{Discussion}

The complex mechanism of the differentiation of preadipocytes into adipocytes is regulated by an interplay of several factors, including the PPAR isoforms $\alpha$ and $\gamma$. These function as important coregulators of lipid homeostasis: PPAR $\alpha$ regulates fatty acid oxidation, primarily in liver and to a lesser extent in adipose tissue, whereas PPAR $\gamma$ serves as a key regulator of adipocyte differentiation and lipid storage. Of the two PPAR $\gamma$ isoforms, PPAR $\gamma 1$ and PPAR $\gamma 2$ - generated by alternative splicing of the same gene - the PPAR $\gamma 1$ isoform is expressed in liver and other tissues, whereas PPAR $\gamma 2$ is expressed exclusively in adipose tissue, where it regulates adipogenesis and lipogenesis. PPAR isotypes are often coexpressed in tissues and an emerging picture is that of a dual and complementary role of PPARs $\alpha$ and $\gamma$ in the regulation of lipid metabolism (Tontonoz et al. 1994, Desvergne \& Walhi 1999).

Rosiglitazone, a synthetic agonist of $\operatorname{PPAR} \gamma$, is able to induce adipocyte differentiation in orbital FGOs (Valyasevi et al. 2002) and, recently, it has been reported that pioglitazone, a synthetic ligand 
A

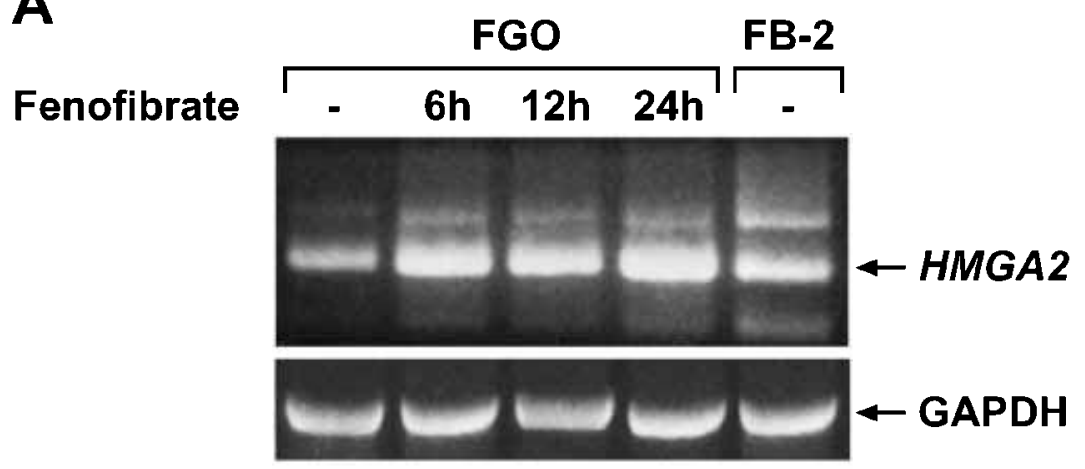

B

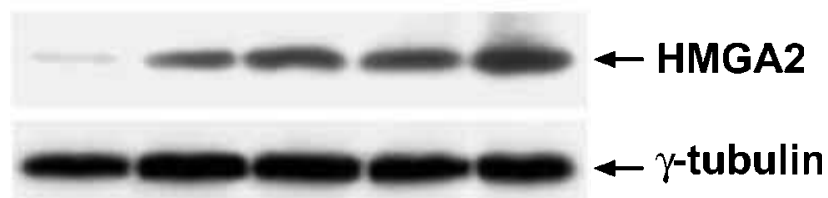

Figure 7 Analysis of HMGA2 expression in FGO adipocyte differentiation. (A) Total RNA was extracted from FGOs that were untreated or treated with fenofibrate at different stimulation times $(0,6,12$ and $24 \mathrm{~h})$ and analysed by RT-PCR. Aliquots $(1 \mu)$ of RNA were reverse transcribed, amplified as described in Materials and methods, transferred to nitrocellulose and hybridized with HMGA2 cDNA. GAPDH was used as internal control for uniform RNA loading. The thyroid carcinoma cell line, FB-2, was used as positive control. (B) Total proteins extracted from non-treated (-) and fenofibrate-treated FGOs were separated (50 $\mu \mathrm{g} / \mathrm{lane})$ on SDS-PAGE and transferred to nitrocellulose membranes. Western blots were first incubated with antibodies specific for HMGA2 protein, and then with horseradish peroxidase-conjugated secondary antibodies. As a control for equal loading, the blotted proteins were stained with Red-Ponceau. In addition, the same western blots were incubated with antibodies to the ubiquitous protein, $\gamma$-tubulin. Proteins were extracted from the cells at time $0,6,12$ and $24 \mathrm{~h}$ of treatment as indicated.

for PPAR $\gamma$, induced reactivation of Graves' ophthalmopathy in a diabetic patient (Starkey et al. 2003). Data on the PPAR $\alpha$ pathway in FGOs are still lacking. Here, we have demonstrated that fenofibrate, a synthetic compound used as a hypolipidaemic agent that binds PPAR $\alpha$, was able to induce a marked appearance of adipocytes in FGOs in vitro. We found that FGOs coexpressed PPAR $\alpha$ and PPAR $\gamma 2$ transcripts at a very high level. This was barely detectable in control fibroblasts. The reason why fenofibrate did not increase PPAR transcripts remains to be determined. One possible explanation could be that PPARs are already upregulated or that fenofibrate does not modulate their expression in this in vitro system but, through PPAR $\alpha$, induces transcription of genes, such as HMGA2, that are related to the early phase of adipocyte differentiation. In fact, treatment of FGOs with fenofibrate significantly increased the expression of HMGA2 evaluated at the mRNA and protein level. This increase had already appeared at $6 \mathrm{~h}$ after fenofibrate induction and there were further increases at 12 and $24 \mathrm{~h}$.

Several studies have associated the expression of $H M G A 2$ with adipocyte proliferation and differentiation in animal models, and here we have shown for the first time that HMGA2 is involved in the pathophysiology of Graves' ophthalmology. This is a further demonstration of the ability of orbital fibroblasts to differentiate towards the adipocyte phenotype after stimulation by fenofibrate. Our data, obtained by both semiquantitative RT-PCR and real-time PCR, demonstrated that fenofibrate significantly increased the expression of leptin in 


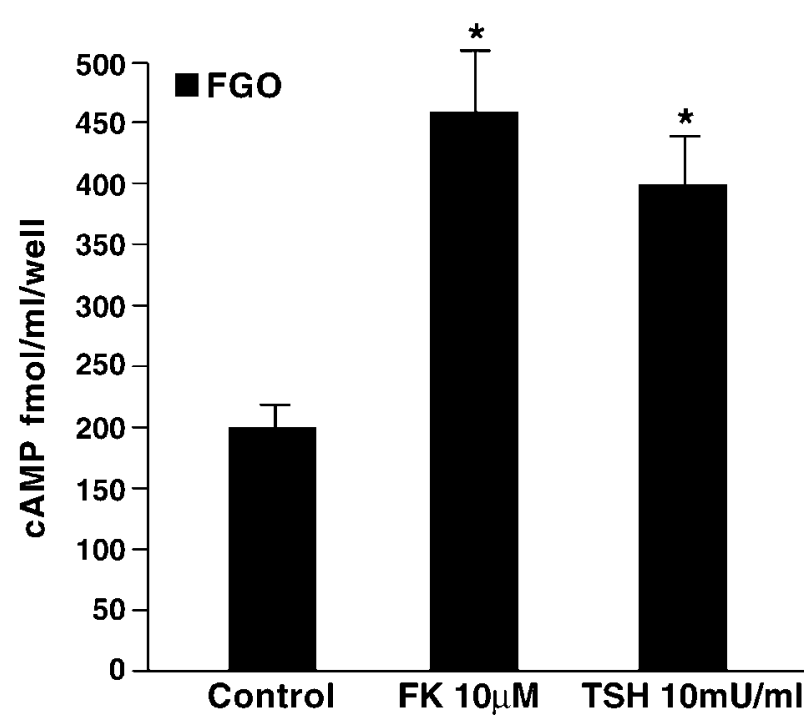

Figure 8 TSH- and forskolin (FK)-stimulated accumulation of cAMP in FGOs. The cells were treated with bovine TSH $10 \mathrm{mU} / \mathrm{ml}$ or FK $10^{-5} \mathrm{M}$ and 3-methyl-1-isobutylxanthine $(0.5 \mathrm{mM})$ for $30 \mathrm{~min}$. Each column represents the mean \pm S.D. $(n=3)$ from at least three separate experiments performed in triplicate. ${ }^{*} P<0.05$ compared with Control.

FGOs, suggesting that actions mediated by PPAR $\alpha$ are important for leptin signalling and maintenance of intracellular fatty acid homeostasis.

Thus orbital FGOs may act as an endocrine compartment that could be linked to the systemic hormonal network; in fact, it expresses leptin, the product of the $o b$ gene (Zhang et al. 1994), usually secreted by adipocytes as an indicator of the size of energy stores, and TSHr. One of the main targets of leptin are the cells of the hypothalamic nuclei that regulate food intake and energy expenditure (Woods et al. 1998). In recent years, several studies have suggested that TSHr may have a role in the pathogenesis of Graves' ophthalmopathy (Feliciello et al. 1993, Bahn et al. 1998, Valyasevi et al. 2002). Our results confirm the link between the adipocyte differentiation of orbital fibroblasts and the appearance of TSHr expression in FGOs (Feliciello et al. 1993, Soriski et al. 1996, Bahn et al. 1998, Valyasevi et al. 2002), showing that fenofibrate is also another inducer of adipogenesis via PPAR $\alpha$ that is able to modulate expression of the $\mathrm{TSH} r$ gene. The TSHr protein appeared to be functional, because TSH treatment significantly stimulated the accumulation of cAMP. Pharmacological modulation of orbital fibroblast growth and adipocyte differentiation may be an important tool with which to control Graves' ophthalmopathy. Previously, we showed that retinoids may modulate the growth and differentiation of orbital FGOs, acting on the cell morphology and apoptosis (Pasquali et al. 2003). Regarding adipocyte differentiation, it is known that retinoic acid treatment induces the opposite effects: it is stimulatory during the early phases and inhibitory at a later stage of terminal differentiation (Shao \& Lazar 1997, Barak et al. 1999). In the latter case, the inhibitory effect seems to be a result of inhibition of the expression of PPARs (Bost et al. 2002). This mechanism could account for the inhibition of cell growth and the apoptosis that are induced by retinoic acid in FGOs.

In conclusion, fenofibrate induced adipogenesis and increased the expression of HMGA2, leptin and TSHr genes in orbital fibroblasts from patients with Graves' ophthalmopathy, showing that the PPAR $\alpha$ pathway also has an important role in the adipocyte differentiation of FGOs. These findings suggest that novel drugs aimed at the antagonism of PPAR $\alpha$, other than the PPAR $\gamma$ signalling system, may also need to be considered in the treatment or prevention of Graves' ophthalmopathy.

\section{Acknowledgements}

This work was supported in part by grants from MIUR 2002, Ateneo and IPSEN to A A S. We are grateful to Dr Joseph Sepe for editing this manuscript.

\section{References}

Anand A \& Chada K 2000 In vivo modulation of Hmgic reduces obesity. Nature Genetics 24 377-380.

Arlotta P, Tai AK, Manfioletti G, Clifford C, Jay G \& Ono SJ 2000 Transgenic mice expressing a truncated form of the high mobility group I-C protein develop adiposity and an abnormally high prevalence of lipomas. Fournal of Biological Chemistry $\mathbf{2 7 5}$ 14394-14400.

Bahn RS, Dutton CM, Natt N, Joba W, Spitzweg C, Heufelder AE 1998 Thyrotropin receptor expression in Graves' orbital adipose/connective tissues; potential autoantigen in Graves' ophthalmopathy. Fournal of Clinical Endocrinology and Metabolism 83 998-1002.

Bandiera A, Bonifacio D, Manfioletti G, Mantovani F, Rustighi A, Zanconati F, Fusco A, Di Bonito L \& Giancotti V 1998 Expression of HMGI(Y) proteins in squamous intraepithelial and invasive lesions of the uterine cervix. Cancer Research 58 426-431.

Barak Y, Nelson MC, Ong ES, Jones YZ, Ruiz-Lozano P, Chien KR, Koder A \& Evans RM 1999 PPAR gamma is required for placental, cardiac, and adipose tissue development. Molecular Cell $\mathbf{4}$ 585-595. 
Basolo F, Giannini R, Toniolo A, Casalone R, Nikiforova M, Pacini F, Elisei R, Miccoli P, Berti P, Faviana P et al. 2002 Establishment of a non tumorigenic papillary thyroid cell line (FB-2) carrying the ret/ptcl rearrangement. International fournal of Cancer 97 608-614.

Battista S, Fidanza V, Fedele M, Klein-Szanto AJ, Outwater E, Brunner H, Santoro M, Croce CM \& Fusco A 1999 The expression of a truncated HMGI-C gene induces gigantism associated with lipomatosis. Cancer Research 59 4793-4797.

Bost F, Caron L, Marchetti I, Dani C, Le Marchand-Brustel Y \& Binetruy B 2002 Retinoic acid activation of the ERK pathway is required for embryonic stem cell commitment into the adipocyte lineage. Biochemical fournal 361 621-627.

Brandes R, Arad R \& Bar-Tana J 1986 Adipose conversion of cultured rat primary preadipocytes by hypolipidemic drugs. Biochimica et Biophysica Acta 877 314-321.

Chiappetta G, Bandiera A, Berlingieri MT, Visconti R, Manfioletti G, Battista S, Martinez-Tello FJ, Santoro M, Giancotti V \& Fusco A 1995 The expression of the high mobility group HMGI (Y) proteins correlates with the malignant phenotype of human thyroid neoplasms. Oncogene 10 1307-1314.

Delerive P, Fruchart JC \& Staels B 2001 Peroxisome proliferator-activated receptors in inflammation control. Fournal of Endocrinology $169453-459$.

Desvergne B \& Wahli W 1999 Peroxisome proliferator-activated receptors: nuclear control of metabolism. Endocrine Review $\mathbf{2 0}$ 649-688.

Falvo JV, Thanos D \& Maniatis T 1995 Reversal of intrinsic DNA bends in the IFN beta gene enhancer by transcription factors and the architectural protein HMG I(Y). Cell 83 1101-1111.

Fedele M, Bandiera A, Chiappetta G, Battista S, Viglietto G, Manfioletti G, Casamassimi A, Santoro M, Giancotti V \& Fusco A 1996 Human colorectal carcinomas express high levels of high mobility group HMGI(Y) proteins. Cancer Research $\mathbf{5 6}$ 1896-1901.

Feliciello A, Porcellini A, Ciullo L, Bonavolonta G, Avvedimento E \& Fenzi G 1993 Expression of thyrotropin receptor mRNA in healthy and Graves' disease retro-orbital tissue. Lancet 342 337-338.

Johnson KR, Lehn DA \& Reeves R 1989 Alternative processing of mRNAs encoding mammalian chromosomal high-mobility-group proteins HMG-I and HMG-Y. Molecular and Cellular Biology 9 2114-2123.

Kopelovich L, Fay JR, Glazer RI \& Crowell JA 2002 Peroxisome proliferator-activated receptor modulators as potential chemopreventive agents. Molecular Cancer Therapy 1 357-363.

Koumas L, Smith TJ, \& Phipps RP 2002 Fibroblast subsets in the human orbit: Thy-1+ and Thy-1 - subpopulations exhibit distinct phenotypes. European Fournal of Immunology 32 477-485.

Kubota N, Terauchi Y, Miki H, Tamemoto H, Yamauchi T, Komeda K, Satoh S, Nakano R, Ishii C, Sugiyama T et al. 1999 PPAR gamma mediates high-fat diet-induced adipocyte hypertrophy and insulin resistance. Molecular Cell 4 597-609.

Manfioletti G, Giancotti V, Bandiera A, Buratti E, Sautiere P, Cary P, Crane-Robinson C, Coles B \& Goodwin GH 1991 cDNA cloning of the HMGI-C phosphoprotein, a nuclear protein associated with neoplastic and undifferentiated phenotypes. Nucleic Acids Research 19 6793-6797.

Pasquali D, Rossi V, Prezioso D, Gentile V, Colantuoni V, Lotti T, Bellastella A \& Sinisi AA 1999 Changes in tissue transglutaminase activity and expression during retinoic acid-induced growth arrest and apoptosis in primary cultures of human epithelial prostate cells. Fournal of Clinical Endocrinology and Metabolism 84 1463-1469.
Pasquali D, Vassallo P, Esposito D, Bonavolontà G, Bellastella A \& Sinisi AA 2000 Somatostatin receptor gene expression and inhibitory effects of octreotide on primary cultures of orbital fibroblasts from Graves' ophthalmopathy. Fournal of Molecular Endocrinology 25 63-71.

Pasquali D, Notaro A, Bonavolontà G, Vassallo P, Bellastella A \& Sinisi AA 2002 Somatostatin receptor genes are expressed in lymphocytes from retroorbital tissues in Graves' disease. Fournal of Clinical Endocrinology and Metabolism 87 5125-5129.

Pasquali D, Bellastella A, Colantuoni V, Vassallo P, Bonavolontà G, Rossi V, Notaro A \& Sinisi AA 2003 All-trans-retinoic acid and $n$-(4-hydroxyphenyl)-retinamide induced growth arrest and apoptosis in orbital fibroblasts in Graves' disease. Metabolism $\mathbf{5 2}$ 1387-1392.

Rosen ED, Sarraf P, Troy AE, Bradwin G, Moore K, Milstone DS, Spiegelman BM \& Mortensen RM 1999 PPAR gamma is required for the differentiation of adipose tissue in vivo and in vitro. Molecular Cell 4 611-617.

Santulli B, Kazmierczak B, Napolitano R, Caliendo I, Chiappetta G, Rippe V, Bullerdiek J \& Fusco A 2000 A 12q13 translocation involving the HMGI-C gene in Richter transformation of a chronic lymphocytic leukemia. Cancer Genetic and Cytogenetic 119 70-73.

Shao D \& Lazar MA 1997 Peroxisome proliferator activated receptor gamma, CCAAT/enhancer-binding protein alpha, and cell cycle status regulate the commitment to adipocyte differentiation. Fournal of Biological Chemistry 272 21473-21478.

Smith TJ 2002 Orbital fibroblasts exhibit a novel pattern of responses to proinflammatory cytokines: potential basis for the pathogenesis of thyroid-associated ophthalmopathy. Thyroid 12 197-203.

Sorisky A, Pardasani D, Gagnon A \& Smith TJ 1996 Evidence of adipocyte differentiation in human orbital fibroblasts in primary culture. Fournal of Clinical Endocrinology and Metabolism $\mathbf{8 1}$ 3428-3431.

Starkey K, Heufelder A, Baker G, Joba W, Evans M, Davies S \& Ludgate M 2003 Peroxisome proliferator-activated receptor-gamma in thyroid eye disease: contraindication for thiazolidinedione use? Fournal of Clinical Endocrinology and Metabolism 88 55-59.

Tontonoz P, Hu E \& Spiegelman BM 1994 Stimulation of adipogenesis in fibroblasts by PPAR gamma 2, a lipid-activated transcription factor. Cell 79 1147-1156.

Valyasevi RW, Harteneck DA, Dutton CM \& Bahn RS 2002 Stimulation of adipogenesis, peroxisome proliferator-activated receptor $\gamma(\operatorname{PPAR} \gamma)$, and thyrotropin receptor by $\operatorname{PPAR} \gamma$ agonist in human orbital preadipocyte fibroblasts. Fournal of Clinical Endocrinology and Metabolism $872352-2358$.

Woods SC, Seeley RJ, Porte D Jr \& Schwartz MW 1998 Signals that regulate food intake and energy homeostasis. Science $\mathbf{2 8 0}$ $1378-1383$.

Zhang Y, Proenca R, Maffei M, Barone M, Leopold L \& Friedman JM 1994 Positional cloning of the mouse obese gene and its human homologue. Nature 372 425-432.

Zhou X, Benson KF, Ashar HR \& Chada K 1995 Mutation responsible for the mouse pygmy phenotype in the developmentally regulated factor HMGI-C. Nature 376 771-774.

\section{Received 30 January 2004}

Accepted 5 April 2004

Made available online as an Accepted Preprint 23 April 2004 